\title{
Hypoxia-associated Component of RR-interval Fluctuations in Patients with Obstructive Sleep Apnea Syndrome
}

\author{
Michiyasu Yamaki", Toshiaki Sato, Hiromi Fujii \\ Department of Occupational Therapy, Yamagata Prefectural University of Health Sciences, Yamagata, Japan
}

Copyright (C) 2015 Horizon Research Publishing All rights reserved.

\begin{abstract}
An RR-interval fluctuation has been used as an important clinical tool for identifying a patient at risk in cardiovascular disease. However, the role of hypoxia on RR-interval fluctuations has not been determined. Methods and Results. We performed ambulatory ECGs monitoring and measured overnight arterial oxygen saturation $\left(\mathrm{SpO}_{2}\right)$ in 26 patients with obstructive sleep apnea syndrome in whom sever hypoxia occurred during sleep. By means of maximal entropy method, time series of ECG-RR intervals were transformed into frequencies. The minimal $\mathrm{SpO}_{2}$ during sleep were compared with spectrum powers of the following frequency ranges; 1) $0.0001-0.05 \mathrm{~Hz}, 2) 0.05-0.1 \mathrm{~Hz}, 3$ ) $0.1-0.15 \mathrm{~Hz}$, 4) $0.15-0.2 \mathrm{~Hz}$, 5) $0.2-0.25 \mathrm{~Hz}$, 6) $0.25-0.3$ $\mathrm{Hz}$, and 7) $0.3-0.5 \mathrm{~Hz}$. Among the seven analyzed frequencies, the increase in the $0.05-0.1 \mathrm{~Hz}$ power of RR-interval fluctuations was linearly correlated with the minimal $\mathrm{SpO}_{2}$ during sleep $(\mathrm{r}=.80, \mathrm{p}<.001)$. Conclusion. This study revealed that hypoxia contributes to $0.05-0.1 \mathrm{~Hz}$ RR-interval fluctuations in patients with obstructive sleep apnea syndrome. RR-interval fluctuations will provide important information about hypoxia.
\end{abstract}

Keywords Hypoxia, RR-interval Fluctuation , Heart Rate Variability, Sleep Apnea Syndrome

\section{Introduction}

RR-interval fluctuations have provided important clinical information $^{1-5}$ for identifying patients at risk in cardiovascular disease. The DIAMOND study showed that the analysis of heart rate dynamics has significant prognostic value that is independent of the clinical risk factors ${ }^{6}$ in patients with depressed left ventricular function after an acute myocardial infarction. However, the underling mechanisms of the RR-interval fluctuation remain unclear. The heart is obligate anaerobe and the heart function is sensitive to hypoxia. Therefore, hypoxia may be responsible for RR-interval fluctuations. We hypothesized that hypoxia induces RR-interval fluctuations. Obstructive sleep apnea causes severe hypoxia attributable to obstruction of the respiratory air way during sleep, while no such abnormality occurs during daytime. Obstructive sleep apnea may be an ideal model when investigating effects of hypoxia on RR-intervals. The goal of this study was to elucidate the contribution of hypoxia to RR-interval fluctuations in patients with obstructive sleep apnea syndrome.

\section{Methods}

\section{Subjects}

This study included 26 patients with obstructive sleep apnea syndrome who fulfilled the standard criteria for obstructive sleep apnea syndrome ${ }^{7}$. Patients were enrolled between 1 December 2012 and 30 November 2013 at Takahata Public Hospital, Takahata, Japan. Exclusion criteria were the presence of atrial fibrillation, atrioventricular block, intraventricular conduction block, pacemaker rhythm, hypotension, because these conditions may interfere appropriate and precise evaluations of RR-intervals or oxygen saturation. This study was approved by the Ethics Committee of Yamagata Prefectural University of Health Science, and the Ethics Committee of Takahata Public Hospital. Written informed consent was obtained from all patients.

\section{Measurements}

ECGs were recorded using NASA and CM5 leads for 24 hours. An ambulatory digital ECG recording device ${ }^{8}$ (FM180; Fukuda Denshi, Tokyo, Japan) with a sampling rate of $1,000 / \mathrm{sec}$ was used with an automatic measurement system (SCM8000; Fukuda Denshi, Tokyo, Japan), and was transferred to a personal computer on which the MemCalc system $^{9-11}$ had been installed (MemCalc/Chiram; Suwa Trust, Tokyo, Japan). Data recording and processing were performed according to the recommendations of the 
European Society of Cardiology and the North American Society of Pacing and Electrophysiology ${ }^{12}$. The MemCalc system was used to transform the RR-interval fluctuations into frequencies. This method allowed us to ascertain how power distributes as a function of frequency (power spectral density estimation) ${ }^{13}$. The analyzed spectral components were 1) $0.0001-0.05 \mathrm{~Hz}$, 2) $0.05-0.1 \mathrm{~Hz}$, 3) $0.1-0.15 \mathrm{~Hz}$, 4) $0.15-0.2 \mathrm{~Hz}, 5) 0.2-0.25 \mathrm{~Hz}, 6) 0.25-0.3 \mathrm{~Hz}$, and 7) $0.3-0.5$ Hz. Each spectral measure was computed as amplitudes i.e. areas under the power spectral density. We defined this parameter as 'spectrum power', and is presented in square milliseconds. We conducted separate analyses during awake and sleep conditions and calculated the sleep/awake ratios as 'spectrum power' during sleep divided by 'spectrum power' during awake. Sleep and awake times were determined by the monitor diary that patients wrote. Further details of the MemCalc system are described elsewhere ${ }^{9}$.

Arterial oxygen saturation $\left(\mathrm{SpO}_{2}\right)$ was measured in all subjects using an LS-300 device (Fukuda Denshi, Tokyo, Japan $)^{14,15}$, that incorporated a finger pulse oximeter (Envitec, Wismar, Germany). The overnight recordings were analyzed using SCM8000 System (Fukuda Denshi, Tokyo, Japan). The lowest oxygen saturation during sleep was defined as the minimal $\mathrm{SpO}_{2}$.

\section{Statistical analysis}

Statistical analyses were performed using Stat View version 5.0 (SAS Institute Inc., Cary, NC, USA). Pearson's correlation was applied to regression analysis. Statistical significance was inferred for $\mathrm{p}<.05$.

\section{Results}

\section{Clinical characteristics of study subjects}

Clinical characteristics of study subjects are presented in table 1 . Twenty six subjects with sleep apnea syndrome were studied. Eight out of 26 patients were treated with continuous positive airway pressure (CPAP) device during sleep. The apnea-hypopnea index (AHI) of study subjects were 5.166.0 per hour. The minimal oxygen saturation during sleep were 53-90\%. Twenty one subjects were also treated as hypertension, 5 as hypercholesterolemia, 3 as diabetes mellitus and one as previous myocardial infarction. Two patients received beta blockade (one hypertension and one previous myocardial infarction). One patient with previous myocardial infarction has reduced left ventricular function with $39 \%$ of ejection fraction by echocardiography. In the other 25 patients, ejection fractions were $57-83 \%$.

Table 1. Clinical characteristics of the study subjects

\begin{tabular}{|c|c|c|c|}
\hline & Number & Mean & Range \\
\hline Age & & 69.4 & $36-86$ \\
\hline Male/female & $19 / 7$ & & \\
\hline AHI $(/ \mathrm{hr})$ & & 30.1 & $5.1-66.0$ \\
\hline minimal $\mathrm{SpO}_{2}(\%)$ & & 79.3 & $53-90$ \\
\hline
\end{tabular}

Abbreviations: CPAP, continuous positive airway pressure; $\mathrm{AHI}$, apnea-hypopnea index; $\mathrm{SpO}_{2}$, arterial oxygen saturation

\section{Comparison with the degree of oxygen desaturation}

Figure 1 shows the power spectrum density of RR-interval time series recorded at the condition with $71 \%$ or $96 \%$ of $\mathrm{SpO}_{2}$ in a patient with obstructive sleep apnea syndrome. The spectral powers during hypoxia were shifted upward to those during normoxia, mainly on the $0.1 \mathrm{~Hz}$ or lower spectral range. This suggests that hypoxia evoked fluctuation of RR intervals. In the same case, the relations of $0.05-01 \mathrm{~Hz}$ powers and $\mathrm{SpO}_{2}$ were plotted by every five-minute (Fig. 2). Increases in $0.05-0.1 \mathrm{~Hz}$ powers in this case were correlated proportionally to decreases in oxygen saturation.

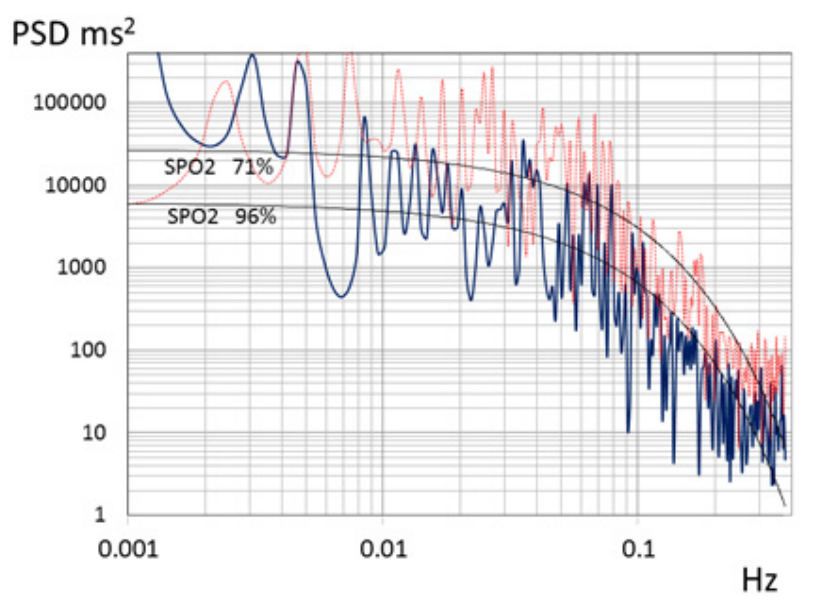

Figure 1. Representative individual trace of PSD in RR-interval time series analyzed during the condition of $71 \%$ and $96 \%$ of $\mathrm{SpO}_{2}$ in a patient with obstructive sleep apnea syndrome

The spectral powers during hypoxia were shifted upward to those during normoxia, mainly on the $0.1 \mathrm{~Hz}$ or lower spectral range. $\mathrm{PSD}$, power spectrum density; $\mathrm{SpO}_{2}$ arterial oxygen saturation.

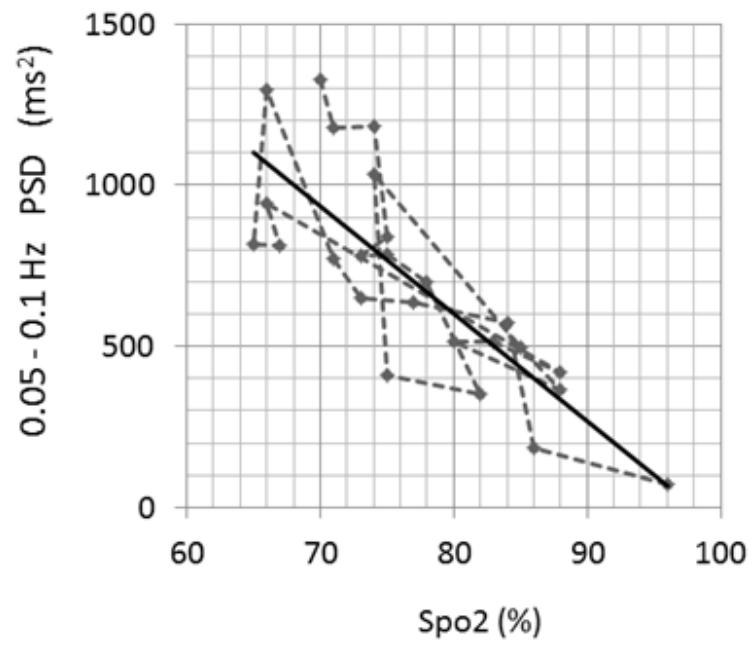

Figure 2. Representative plots of $0.05-01 \mathrm{~Hz}$ powers and $\mathrm{SpO}_{2}$ measured by every five-minute during sleep in a patient with obstructive sleep apnea syndrome..

The spectrum power and $\mathrm{SpO}_{2}$ were varied each time. However, linear relations were observed between them. PSD, power spectrum density; $\mathrm{SpO}_{2}$, arterial oxygen saturation. 

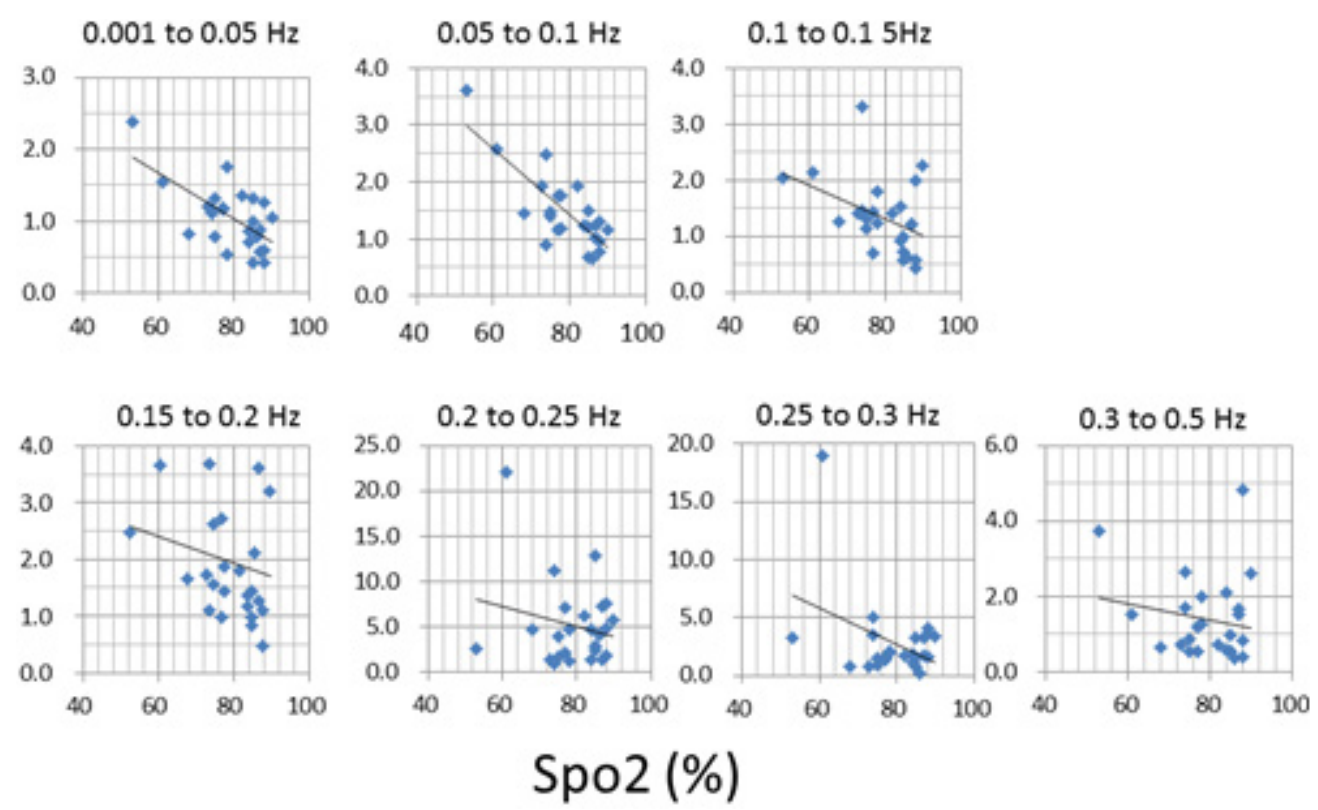

Figure 3. Correlation between the sleep/awake ratio of spectral powers and the minimal $\mathrm{SpO}_{2}$ during sleep.

We investigated the correlations in all subjects. Seven spectra were analyzed separately: 1) $0.0001-0.05 \mathrm{~Hz}, 2$ ) $0.05-0.1 \mathrm{~Hz}$, 3) $0.1-0.15 \mathrm{~Hz}$, 4) $0.15-0.2 \mathrm{~Hz}$, 5) $0.2-0.25 \mathrm{~Hz}$, 6) $0.25-0.3 \mathrm{~Hz}$, or 7) $0.3-0.5 \mathrm{~Hz}$. We calculated the sleep/awake ratio of spectral powers. They were compared to the minimal $\mathrm{SpO}_{2}$ during sleep (Fig. 3). Among the seven analyzed frequencies, we found that the sleep/awake ratios of $0.05-0.1 \mathrm{~Hz}$ power was linearly correlated with the minimal $\mathrm{SpO}_{2}$ during sleep $(\mathrm{r}=.80, \mathrm{p}<.001)$. Those of $0.0001-0.05 \mathrm{~Hz}$ power also showed significant but week correlations $(\mathrm{r}=.65, \mathrm{p}<.05)$ with the minimal $\mathrm{SpO}_{2}$

The correlation coefficient was $0.65(\mathrm{p}<.05)$ in $0.0001-$ $0.05 \mathrm{~Hz}, 0.80(\mathrm{P}<.001)$ in $0.05-0.1 \mathrm{~Hz}, 0.41$ (not significant; NS) in $0.1-0.15 \mathrm{~Hz}, 0.21(\mathrm{NS})$ in $0.15-0.2 \mathrm{~Hz}, 0.22$ (NS) in $0.2-0.25 \mathrm{~Hz}, 0.39$ (NS) in $0.25-0.3 \mathrm{~Hz}$, or 0.17 (NS) in $0.3-$ $0.5 \mathrm{~Hz}$. The sleep/awake ratio of $0.05-0.1 \mathrm{~Hz}$ spectrum powers were most closely correlated with the minimal $\mathrm{SpO}_{2}$. PSD, power spectrum density; $\mathrm{SpO}_{2}$, arterial oxygen saturation.

\section{Discussion}

Results showed that hypoxia evokes RR-interval fluctuations in obstructive sleep apnea syndrome. Among the seven analyzed frequencies, we found that the increase in the $0.05-0.1 \mathrm{~Hz}$ power correlated linearly with the minimal $\mathrm{SpO}_{2}$ during sleep. This evidence indicates that the RR-interval fluctuations, especially $0.05-0.1 \mathrm{~Hz}$ fluctuations will provide important information related to hypoxia.

\section{Hypoxia and RR-interval fluctuations}

Previously, chronic effects of hypoxia were reported by Cornolo et al. ${ }^{16}$ in subjects staying at high altitude. They found that $0.04-0.15 \mathrm{~Hz}$ components (low-frequency components) of RR-interval fluctuations decreased after a six-day stay at the high-altitude mountain. However, acute effects of hypoxia were not clear. Several studies have examined that in subjects staying at the hypoxic chamber $^{17-19}$, where oxygen contents were low. However, these studies failed to detect the relation between hypoxia and RR-interval fluctuations. Differences in study design from the present study were 1) degree of hypoxia and 2) analyzed spectrum bands. Patients with obstructive sleep apnea syndrome are exposed by severe hypoxia during sleep, therefore their sleep are interrupted. If the air way is obstructed completely, then the oxygen supply stops completely. Hypoxia caused by obstructive sleep apnea might be more severe than that caused by reduction of air oxygen content. Moreover, we analyzed seven narrow spectra of RR-interval fluctuations separately. These analytical methods helped us determine the relations sharply and specifically. Finally, the results clearly revealed the presence of hypoxia-related components within the RR-interval fluctuations.

\section{Origin of RR-interval fluctuations}

The spectrum of hypoxia-related RR-interval oscillation was categorized into low frequency in heart rate variability analysis. Oscillations of this category were explained to be associated with baroreflex activation and to be jointly regulated by sympathetic and parasympathetic interaction ${ }^{20}$. However, a recent study showed that the baroreflex sensitivity was suppressed in patients with sleep apnea syndrome $^{21}$. Moreover, several studies suggested that the altered heart rate variability is associated with various pathologic conditions such as hemorrhagic shock ${ }^{22}$ and septic shock ${ }^{23}$. We supposed that the previous explanation does not cover all of RR-interval fluctuations; the other mechanisms might influence pathological fluctuations. Hypoxia may be a new candidate origin of pathological fluctuations. However, interactions between hypoxia and RR 
fluctuation remain unclear. Possible mechanisms were oscillatory changes in 1) pacemaker potentials in sinus node, 2) disturbed electrical conductions in conduction system and 3) mechanical stretch in ventricular muscle cells. Further studies will be necessary to determine the mechanism of this phenomenon.

\section{Clinical implication and limitation}

This study revealed that RR-interval fluctuations were associated with hypoxia. This might be a key to the understanding of a prognostic value of RR-interval fluctuation in cardiovascular disease ${ }^{5}$. Previously, we reported in an experimental model that the depolarization fluctuations directly triggered ventricular fibrillation on the heart with high-dose loading of sodium channel blocker ${ }^{24}$. Since depolarization fluctuations can be seen as RR interval fluctuations in a conventional ECG recording, hypoxia-associated fluctuation may trigger life-threatening events. With consideration of these relations, more attention should be paid to the RR-interval fluctuations, especially $0.05-0.1 \mathrm{~Hz}$ fluctuations.

The criticisms in this study are study size and population. The study size was small, and the study population was limited to patients with obstructive sleep apnea syndrome. Additional research conducted with a large study size and in other pathological conditions associated with hypoxia is required.

\section{REFERENCES}

[1] Kleiger RE, Miller JP, Bigger JT Jr, Moss AJ. the Multicenter Post-Infarction Research Group. Decreased heart rate variability and its association with increased mortality after myocardial infarction. Am J Cardiol 1987;59:256-62.

[2] Bigger JT Jr, Fliess GL, Steinmann RC, Rolnitzky LM, Kleiger RE, Rottman JN. Frequency domain measures of heart period variability and mortality after myocardial infarction. Circulation 1992;85:164-71.

[3] Zuanetti G, Neilson JM, Latini R, Santoro E, Maggioni AP, Ewing DJ. Prognostic significance of heart rate variability in post-myocardial infarction patients in the fibrinolytic era: the GISSI-2 results. Circulation 1996;94:432-6.

[4] Tsuji H, Larson MG, Venditti FJ Jr, Manders ES, Evans JC, Feldman CL, Levy D. Impact of reduced heart rate variability on risk for cardiac events: the Framingham Heart Study. Circulation 1996;94:2850 -5.

[5] La Rovere MT, Bigger JT Jr, Marcus FI, Mortara A, Schwartz PJ. Baroreflex sensitivity and heart-rate variability in prediction of total cardiac mortality after myocardial infarction. Lancet 1998;351:478-84.

[6] Huikuri HV, Mäkikallio TH, Peng CK, Goldberger AL, Hintze U, Møller M. Fractal correlation properties of R-R interval dynamics and mortality in patients with depressed left ventricular function after an acute myocardial infarction. Circulation 2000; 101: 47-53.
[7] Epstein LJ, Kristo D, Strollo PJ, Friedman N, Malhotra A, Patil SP, Ramar K, Rogers R, Schwab RJ, Weaver EM, Weinstein MD; Adult Obstructive Sleep Apnea Task Force of the American Academy of Sleep Medicine. Clinical guideline for the evaluation, management and long-term care of obstructive sleep apnea in adults. J Clin Sleep Med 2009;5:263-76.

[8] Shiraishi M, Kamo T, Kamegai M, Baevsky RM, Funtova II, Chernikova A, Nemoto S, Hotta M, Nomura Y, Suzuki T. Periodic structures and diurnal variation in blood pressure and heart rate in relation to microgravity on space station MIR. Biomed Pharmacother. 20048 Suppl 1:S31-4.

[9] Ohtomo N, Terauchi S, Tanaka Y, Tokiwano K, Kaneko N. New Method of Time Series Analysis and Its Application to Wolf's Sunspot Number Data. II: Periodicities of The Daily Sunspot Numbers. Jpn J Appl Phys 1997;36 : 957-68.

[10] Murasato Y, Hirakawa H, Harada Y, Nakamura T, Hayashida Y. Effects of systemic hypoxia on R-R interval and blood pressure variabilities in conscious rats. Am J Physiol 1998 ;275: H797-804.

[11] Nishimura M, Hashimoto T, Kobayashi H, Fukuda T, Okino K, Yamamoto N, Nakamura N, Yoshikawa T, Takahashi H, Ono T. Association between cardiovascular autonomic neuropathy and left ventricular hypertrophy in diabetic haemodialysis patients. Nephrol Dial Transplant 2004; 19: 2532-8.

[12] Task Force of the European Society of Cardiology, North American Society of Pacing and Electrophysiology. Heart rate variability: standards of measurement, physiological interpretation and clinical use. Circulation 1996;93: 104365 .

[13] Kay SM, Marple SL. Spectrum analysis: A modern perspective. Proc IEEE 1981; 68:1380-419.

[14] Takasugi N, Nishigaki K, Kubota T Tsuchiya K, Natsuyama K, Takasugi M, Nawa T, Ojio S, Aoyama T, Kawasaki M, Takemura G, Minatoguchi S. Sleep apnoea induces cardiac electrical instability assessed by T-wave alternans in patients with congestive heart failure. Eur J Heart Fail 2009; 11:1063-70.

[15] Holland RP, Brooks H. The QRS complex during myocardial ischemia: an experimental analysis in the porcine heart. J Clin Invest 1976; 57: 541-50.

[16] Cornolo J, Mollard P, Brugniaux JV, Robach P, Richalet JP. Autonomic control of the cardiovascular system during acclimatization to high altitude: effects of sildenafil. J Appl Physiol 2004;97:935-40.

[17] Yamamoto Y, Hoshikawa Y, Miyashita M. Effects of acute exposure to simulated altitude on heart rate variability during exercise. J Appl Physiol 1996; 81:1223-9.

[18] Lucy SD, Hughson RL, Kowalchuk JM, Paterson DH, Cunningham DA. Body position and cardiac dynamic and chronotropic responses to steady-state isocapnic hypoxaemia in humans. Exp Physiol 2000;85:227-37.

[19] Huang SC, Wong MK, Wang JS. Systemic hypoxia affects cardiac autonomic activity and vascular hemodynamic control modulated by physical stimulation. Eur J Appl Physiol 2009;106:31-40.

[20] Mirvis DM, Goldgerber AL. Electrocardiography. In Bonow 
RO, Mann DL, Zipes DP, Libby P, eds: Braunwald's Heart Disease. Ninth edition. Philadelphia, PA: Elsevier Saunders ,2012, pp,126-65.

[21] Carlson JT, Hedner JA, Sellgren J, Elam M, Wallin BG. Depressed baroreflex sensitivity in patients with obstructive sleep apnea. Am J Respir Crit Care Med 1996;154:1490-6.

[22] Cooke WH, Convertino VA: Heart rate variability and spontaneous baroreflex sequences: Implications for autonomic monitoring during hemorrhage. J Trauma Inj Infect Crit Care 2005; 58:798-805.
[23] Soriano F, Nogueira A, Cappi S, Lins M, Hoshino W, Gonzaga L. Heart dysfunction and heart rate variability prognoses in sepsis. Crit Care 2005; 8: P75.

[24] Watanabe T, Yamaki M, Kubota I, Tachibana H, Tomoike H.. Relation between activation sequence fluctuation and arrhythmogenicity in sodium-channel blockades. Am J Physiol 1999, 277: H971-7. 